POLSKA AKADEMIA UMIEJĘTNOŚCI

TOM XIII

KULTURA SŁOWIAN. ROCZNIK KOMISJI KULTURY SŁOWIAN PAU

2017

DOI 10.4467/25439561KSR.17.005.7875

\title{
ЕЛЕНА БОНДАРЕВА
}

Сретенская духовная семинария

Фонд исторической перспективы

Москва

\section{СЛАВЯНСТВО КАК ПРЕДМЕТ ИЗУЧЕНИЯ: ОТ ЛАВРЕНТИЯ СУРОВЕЦКОГО ДО ФЕДОРА ТАРАНОВСКОГО}

\author{
SLAVS AS THE RESEARCH SUBJECT: \\ FROM LAURENT SUROWIECKI \\ TO FYODOR TARANOWSKI
}

\begin{abstract}
Streszczenie
Jeśli rozumieć pojęcie geokultura maksymalnie szeroko, to należy w nie włączyć kulturę budowy państwowości oraz związaną z tym procesem samoświadomość narodu. Wydaje się to aktualne dziś, kiedy na ukształtowane przez historię instytucje państwowe oddziałuje globalizacja. Szkoła wiedzy o państwie i porównawcze studia prawa Słowian zrodziły się w wielu państwach w XIX w., ale największy rozkwit osiągnęły w Polsce. Należy odnotować, że Polska miała wybitnych przedstawicieli tzw. teorii wspólnoty słowiańskiej, choć bardziej znane są nazwiska F. Palackiego, L. Stura, P. Szafarzyka. „Polskość” w historiografii przyćmiła ten kierunek, który uznawał Słowian jako integralny przedmiot badań. Jednak u zarania teorii wspólnoty słowiańskiej dostrzegamy badania Wawrzyńca Surowieckiego, autora Badań początków narodów Stowiańskich z 1828 r.

W dziedzinie historii prawa Słowian przoduje Wacław Maciejewski. On swoim monumentalnym dziełem Historia prawodawstw słowiańskich zapoczątkował nowy kierunek badań, objął nimi wszystkie narody słowiańskie, tworząc syntezę historii prawodawstwa Słowian. Jego badania kontynuował rosyjsko-polski historyk prawa i filozof Fiodor Taranowski. Dowodził tezy, że wszystkie narody słowiańskie należą do Europy. Wyrażał zdziwienie, że niektórzy Słowianie wyrzekają się swojej słowiańskości. Obca mu była romantyczna idealizacja słowiańskiej historii. Badał realną duchową, społeczną i materialną kulturę Słowian ze szczególnym uwzględnieniem Polski.
\end{abstract}




\section{Summary}

Understanding the notion of geoculture as broadly as possible requires including the culture of nationhood-building and self-consciousness of the nation connected with the process. It seems to be up-to-date now when globalization has impact on state institutions which are shaped by history. The school of knowledge about the state and comparative law studies of the Slavs came into existence in many countries in the $19^{\text {th }}$ century, but reached the greatest prosperity in Poland. It should be noted that Poland had outstanding representatives of the socalled Slavic community theory, although more familiar are the names of F. Palacki, L. Stur and P. Szafarzyk. "Polishness" in historiography overshadowed the trend which acknowledged the Slavs as an integral subject of research. However, at the beginning of the Slavic community theory, we come across the research of Wawrzyniec Surowiecki, the author of The Research on the Origins of the Slavic Nations from 1828.

The leader in the field of law history of the Slavs is Waclaw Maciejewski. His monumental work: The History of Slavic Legislation initiated a new trend of research which covered all the Slavic nations, creating a synthesis of the history of Slavic legislation. His research was continued by the Russian-Polish law historian and philosopher Fyodor Taranowski. He argued that all Slavic nations belonged to Europe. He expressed astonishment that some Slavs renounced their Slavic nature. Romantic idealization of Slavic history was alien to him. He studied real, spiritual, social and material culture of the Slavs, with particular emphasis on Poland.

Słowa klucze: Słowianie, kultura państwowości, prawo Key words: Slavs, culture of nationhood, law

Если понимать геокультуру максимально широко, то в ее состав невозможно не включать государственную культуру, культуру государственного строительства и осмысление этого процесса в самосознании народа. Думается, что это тем более актуально в наше время, когда исторические институты претерпевают глобальные трансформации. Мы принимаем определение, данное Б. Межуевым, рассматривающим геокультуру как совокупность культурных оснований, обеспечивающих связность и легитимность пространств даже в период «их политического развода». В этом смысле для геокультуры славянских народов чрезвычайно важны такие понятия, как геокультурные общности, геокультурные связи и геокультурная периферия. Ученые-слависты не использовали этот понятийный аппарат, но они исследовали именно эти явления. В особенности применимы к предмету сравнительного славянского права категории геокультурных образов - по Д. Замятину: «системы наиболее мощных, ярких и масштабных геопространственных знаков, символов, характеристик, описывающих особенности развития и функционирования тех или иных культур и/или цивилизаций в глобальном контексте ${ }^{1}$ ».

${ }^{1}$ Д. Замятин, Культура и географические образы, http://gtmarket.ru/laboratory/expertize/3223, дост. 11.09.2017. 
Мы видим свою задачу в том, чтобы напомнить несколько выдающихся имен и исследовательских направлений, достаточно распространенных в XIX начале XX века в славянских странах, но практически вытесненных из современной науки. Школа государствоведения и сравнительного изучения славянского права сложилась во многих странах в XIX веке, но наибольшего расцвета она достигла именно в Польше. Стоит также отметить, что в Польше были свои и весьма выдающиеся представители так называемой теории славянской взаимности, хотя нам более известны имена Ф. Палацкого, Л. Штура, П. Шафарика. «Польскость» несколько затмила в историографии то направление, которое рассматривало славянство как целостный предмет изучения.

У истоков теории славянской взаимности также стоит польский историк Вавженец (Лаврентий) Суровецкий, книгу которого «Исследование начала народов славянских», написанную в 1828 году, на русском языке издал в сокращенном варианте О. Бодянский, сопроводив ее такими словами: «До Суровецкого все исследователи старались отыскать прямо или косвенно Славян в том или ином великом народе древности, но он первый после многолетних и глубоких разысканий и соображений убедился, что Славян должно искать у Славян и, притом, оставив Азию.., ограничиться одной Европой, в которой они были такой же самостоятельный народ, как и другие, сходные с ним, более или менее своей численностью»².

П. Шафарик предварил свое широко известное сочинение «О происхождении славян» такими словами: «Я благодарен господину Суровецкому за щедрое обучение и нравственное укрепление... Ему нельзя отказать в основательности изучения источников, рассудительности, яркой терминологии и целесообразности построений» ${ }^{3}$.

К плеяде польских славистов «романтического периода» можно отнести и Зориана Доленгу-Ходаковского, наследие которого и сейчас до конца не освоено, и Самуила Линде, и трудившегося уже позднее выдающегося лингвистафилософа Т. Лер-Сплавиньского. В сфере же особенно нам интересной истории славянского права возвышается фигура Вацлава Александра Мацеевского

Он, собственно, по мнению многих ученых, и явился творцом особой научной дисциплины в середине XIX века - истории славянского права своим монументальным трудом Historia prawodawstw slowiańskich. «Мацеевский своим исследованием обнял все славянские народы, ни одного из них не исключил и не упустил, всем уделил одинаковое внимание и дал для всех них одно совокупное

2 Л. Суровецкий Л. Исследование начала народов славянских: Рассуждение, чит. в торжеств. заседании Вари. о-ва любителей наук, 24 янв. 1824 г. д. чл. его, Лаврентием Суровецким, пер. с пол. Ю. Белявский, [Предисл.: О. Бодянский], Л. Суровецкий, О-во истории и древностей рос., Москва 1846.

3 P. Šafařík Über die Abkunft der Slawen nach Lorenz Surowiecki, Ofen 1828.

${ }^{4}$ W. Maciejowski, Historya prawodawstw slowiansk, Tom I, Wydanie drugie, Warszawa, 1856. 
историко-юридическое построение. Построение это по приемам конструкции распадается на две различные части, - эпоху до X века и эпоху с X века до конца XVIII столетия, на котором историко-юридическое исследование Мацеевского остановилось. До X века Мацеевский дал интегральный образ единого славянского права, не дифференцированного по отдельным славянским народностям. Начиная с $\mathrm{X}$ века и далее он дал сравнительно-историческую конструкцию прав всех славянских народов, в которой находит себе место всякий из них со своими специфическими особенностями» ${ }^{5}$.

Для нас особенно важно подчеркнуть подход ученого к славянству как интегральному явлению и особому предмету историко-юридического изучения. Этим он отличался как от предшественников, так и от последующих исследователей этой проблематики. Уже к концу XIX века фокус внимания исследователей переместился на изучение национального права отдельных славянских народов, и это совершенно необходимый и оправданный этап в развитии науки. Однако внутри этого процесса перехода по-прежнему сказывалось влияние труда Мацеевского на том, «что историю права отдельных славянских народов стали теперь изучать не обособленно, а сравнительно с остальными национальными системами права славянского племени. Благодаря этому получилась возможность установить исходные точки развития, чего нельзя было сделать на основании одного лишь национального материала. Затем, в виду наличности единства происхождения и общих черт сходства, при изучении права древнего периода того или другого славянского народа, не обладающего прямыми своими источниками для данной эпохи, стали прибегать для восстановления полной картины правового строя данного времени к аналогиям из права других славянских народов, более богатых соответственными источниками. Таким образом, на место сравнительно-исторического изучения целокупного славянского права явился сравнительно-славянский метод разработки национальной истории права отдельных славянских народов» ${ }^{6}$.

В каждой из славянских стран на этом этапе появляются свои специалисты по истории права. В России это Ф. Леонтович и М.Ф. Владимирский-Буданов, которые развили уже существующую и блестяще реализованную Н.М. Карамзиным в Истории государства Российского традицию давать очерк памятников государственной и юридической культуры. В деле применения сравнительно-славянского метода плодотворно поработали польские ученые, к примеру О. Бальцер

5 Ф. Тарановский, Славянство как предмет историко-юридического изучения, цит. по Бондарева Е.A. Pax Rossica, Русская государственность в трудах историков зарубежья, Вече, Москва 2012, с. 200.

6 Там же, c. 206.

${ }^{7}$ O. Balzer, Narzaz w systemie danin książęcych pierwotnej Polski, Lwów 1928. s. 76-77, 90-110, 160-161, 162-164, 169, 174, 176-177 i n.; O. Balzer, Historya porównawcza praw stowiańskich. Główne kierunki rozwoju nauki i jej istotne zadanie, Lwów 1900 (Studia nad historią prawa polskiego wydawane pod redakcją Oswalda Balzera, tom I, zeszyt 5). 
Однако на переломе веков набрала силу иная тенденция - тенденция отхода от некоего общего славянского наследия. В Польше стала выходить Польская Энциклопедия, редактируемая и издаваемая Краковской академией умния. Она подводила итоги многовековой польской культуры. Поставлен был вопрос и об истоках этой культуры. Они, несомненно, как и следовало ожидать, коренились в славянстве, но, что явилось уже новшеством, только в западном славянстве. Народившаяся в польских научных кругах мысль об ограничении или сосредоточении историко-юридического изучения славянства в пределах западных славян принялась и дала свои ростки. В восстановленной Польше был учрежден в 1921 году в Познани Западно-славянский институт, в круг его исследовательских задач входила и история западнославянского права. Институт имел свой специальный печатный орган - «Slavia Occidentalis». В приведенном сужении славянства, как предмета историко-юридического изучения, до одного лишь славянства западного Ф.В. Тарановский усматривал топографическое самоограничение исследования. Плодотворное в этом отношении значение изучения западного славянства для разработки истории польского права уже несомненно сказалось в работе польского историка Сигизмунда Войцеховского о происхождении польского государства, в которой автор путем сравнения с политическим строем полабских славян (ободритов и лютичей) удачно раскрывает бывшие до сих пор неясные пути и формы политической организации польских земель в эпоху до Пяста. Затем выделение западного славянства как специального замкнутого в себе предмета историко-юридического изучения имело значение и для интенсификации исследовательского труда по тому расплетению и разложению переплетенных и слившихся элементов первоначальной славянской и позднейшей германской правовой культуры.

Но есть в указанном западнославянском течении и слабая сторона. Она обнаружилась при первой же попытке выставить западное славянство как нечто в порядке историко-юридического изучения самодавлеющее. Как мы уже знаем, эта попытка была сделана Краковской академией умения, и по ее приглашению К. Кадлец дал очерки по первобытному до X века праву западных славян, но, само собою разумеется, к построению его привлек материал и южных, и восточных славян, ибо без него нельзя было бы исполнить возложенную задачу. Текст и примечания упомянутых очерков так и пестрят цитатами из Русской Правды, да и все это западнославянское право до Х века ничем не отличается от общеславянского права за то же время. Затем в дальнейшем оказалось, что западнославянское право, при том в его наиболее выдвинутых на запад проявлениях, обнаруживает черты разительного сходства с правом восточнославянским. Этот неожиданный для западнославянского течения факт нельзя не подчеркнуть. Феликс Конэчны, автор истории России подчеркивает торговый городской характер древнейшего русского боярства как нечто несоизмеримое с общественно- 
политическим развитием в Европе и западным славянам совершенно чуждое 8 Между тем исследование профессора К. Тыменецкого о городском устройстве у балтийских славян наглядно показало, что такой же точно городской и торговый характер носили передние мужи у этой самой западной ветви славянства $^{9}$. Несмотря на очевидность слабых сторон, мысль о западном славянстве как о самодовлеющем объекте историко-юридического изучения крепнет особенно после того, как удалось ей найти для себя новые питательные соки на почве, так называемого, «среднеевропейского права». Ф. Тарановский подчеркивает, что для этого этапа историко-правовой науки характерно отталкивание от общеславянского фундамента и поиск иного родства - среднеевропейского единства. И тут уместно вспомнить Томаша Массарика и теорию «Миттельевропы». Интересно, что и в России наблюдаются сходные процессы поиска иного родства. Так течение евразийцев ищет родственные черты и корни совсем в противоположном направлении - в туранской степной империи и роднит наши Земские соборы с монгольским курултаем!

Развитие науки, тем не менее, все расставило на свои места. Маятник пришел в равновесие. Между западным и восточным славянством нет той степени разобщения, что подтвердили и многие польские ученые: О. Халецкий, Ст. Кутшеба. Местом встречи западного и восточнославянского права можно считать литовско-русское право, которое, таким образом, составляет связующее звено.

Нам могут возразить, что нет единого славянского права так же, как нет и единого славянского языка, и что праславянское право и праславянский язык только конструируются сравнительно-исторически. И это именно так. Но ведь необходимо пойти дальше и сказать, что в древнем периоде нет и единого русского, польского, чешского, сербского и других национальных прав, а имеется лишь большое разнообразие сходных, но все же и по содержанию и по пространству действия различных юридических обычаев. И тем не менее мы конструируем и национальное, и славянское право, и эти сравнительно-исторические конструкции являются научными реальностями в деле восстановления и объяснения исторического прошлого права и его развития. Заслуга Мацеевского и его прямого последователя по методам работы и мировоззрению Федора Тарановского как раз и состоит в том, что сравнительно-исторический метод позволяет восстановить правовой контекст эпохи, найти адекватную оценку того или иного памятника или процесса в общемировом плане и восстановить утраченные фрагменты, используя метод сравнительной реконструкции.

${ }^{8}$ F. Koneczny, Dzieje Rosji, t. 1, Do roku 1449, Warszawa 1917.

${ }^{9}$ K. Tymieniecki, Wczesne dzieje miasta europejskiego, „Przegląd Historyczny” 1966, 57/1, s. $137-153$. 
Блестящий пример применения «школы Мацеевского» дает творчество русско-польского историка, правоведа, философа Федора Васильевича Тарановского. Родился он в 1875 году в Плонске. Отец из православного духовенства Волыни, мать из обедневшей шляхетской семьи, закончил гимназию и юридический факультет университета в Варшаве. Его профессорами были Ф. Зигель, Ф. Леонтович и отец великого поэта А.Л. Блок. Как необыкновенно талантливый молодой ученый он уже в 1889 году получил доцентуру в Варшавском университете по кафедре энциклопедии права. Его первые большие работы сразу обратили на себя внимание: Сравнительное правоведение в конце ХІХ века, Феодализм в России, Политическая доктрина в Наказе императрицьь Екатеринь II, Юридический метод в государственной науке. Очерк его развития в Германии. В 1908 году он стал профессором Юрьевского университета, а в 1917 - получает кафедру в Петроградском университете. В 1920 году семья Тарановских эмигрирует на Балканы, и в течении 16 лет ученый возглавляет Кафедру истории права славянских народов в Беградском университете. Кроме множества сравнительно мелких монографий на разных языках по теории и истории права и 34 чрезвычайно ценных обзоров новейшей литературы по истории права славянских народов, он прославил Кафедру выдержавшим два издания Введением в историю права славян $(1923,1933)$ на сербском языке, трехтомною Историею сербского права в державе Неманей (1931 - 1935) на сербском языке, академическою речью Законодательство Карла IV и Стефания Душана, написанную им по предложению председателя Научного общества во Львове П. Домбковского на польском языке Историею русского государственного устройства (1928) и изданным в Харбине анализом Элементов основных законов в Уложения Царя Алексея Михайловича (1928). Внешним выражением признания его ученых заслуг было звание члена трех академий и председателя Русского научного института в Белграде.

Одновременно с напряженною ученою и учебною работою жизнь Ф.В. Тарановского в эмиграции была занята деятельным участием в русской академической и общественной жизни. Сверх того, он оказал ценные услуги разным югославянским и общеславянским культурным начинаниям, за что был избран членом-корреспондентом Славянского института в Праге, членом Львовского научного общества и почетным членом Матицы Сербской.

Его основной специальностью первоначально была история русского права, но он не мыслил ее вне связи с правом других славянских народов. Прекрасно владея славянскими и европейскими языками, досконально овладев всем фондом правовых памятников западных славян, в первую очередь поляков, изучив и введя в научный оборот достижения правовой культуры южных славян, в первую очередь сербов, Тарановский смог адекватно оценить уровень и оригинальность русской государственной культуры. Его позицию очень точно охарактеризовал Е. Спекторский: 
«Славянофильская идеализация отечественной истории, западническое преклонение перед чужеродными установлениями, евразийство с его предвзятою «ставкою на мусульманский восток», высокомерное отношение к «низкой» Византийской империи (bas Empire), взгляд на еe, как никак, тысячелетнюю историю как на гниение, также как и некритическое восхищение всем, что идет от Византии, марксизм с его подведением исторического процесса под заранее заготовленные схемы - все это казалось ему посягательством на истину с заранее обдуманным намерением. И из многочисленных теоретических направлений или «измов» он в объективной науке как историк допускал только историзм, т.е. последовательное применение исторического метода... Его мировоззрение было проникнуто тремя мотивами: всероссийским патриотизмом, разумным славянолюбием и преданностью христианству» ${ }^{10}$.

В своих многочисленных работах Ф.В. Тарановский неизменно исходил из того, что все славянские народы суть народы европейские. Отмечал общее и особенное в характеристиках разных славянских народов и изумлялся нигилизму тех славян, которые отрицают славянство и отрекаются от него, воображая, что именно благодаря этому они оказываются особенно передовыми. Его идеалом была не изоляция отдельных славянских народов и не субординация одних славян другими, а их братская координация. При этом он был чужд восторженной, но часто безграмотной романтической идеализации славянской истории. Он исследовал не фантазии, а реальную духовную, социальную и материальную культуру славян. Им много сделано по польской истории ${ }^{11}$.

Тарановский в годы эмиграции изучил и подготовил к публикации множество южнославянских памятников права и создал специальный курс по этой дисциплине, в результате совершенно заслуженно стал академиком Сербской академии наук. Но все же наибольшую честь ему, как ученому должны отдавать мы - русские. Он создал выдающиеся работы по русской государственной и правовой истории, ему принадлежит историко-философское эссе Государственная культура России, которое является и итогом многолетней работы исследователя, и признанием в любви к Отечеству, и ответом на либеральную и марксистскую трактовку русской истории как беспочвенное чужебесие, так и доморощенную кичливость.

В этом эссе во имя строгой науки разоблачается представление о так называемом царизме, вызванное ненавистью к христианскому характеру русского

${ }^{10}$ Е. Спекторский, Жизнь и творчество Ф.В. Тарановского, цит. по: Pax Rossica..., c. 181.

${ }^{11}$ F.Taranowski, Historia prawa poludniowostowiańskiego, Pamietnik historyczno-prawny pod redakcją Przemyslawa Dąbkowskiego, tom III, zeszyt 5, Lwów 1927, s. 19-25. Статья в сборнике: Ksiega pamiatkowa ku czci Oswalda Balzera, tom II, Lwow 1925, s. 590-591. Доклад на Конференции историков восточно-европейских и славянских государств в Варшаве в 1927 г., Conference etc., II-me partie, pp. 241-250, 252-260. 
государства. Тарановский убедительно доказывает, что прежде всего историческое развитие русской государственности вполне укладывается в рамки политической эволюции европейской культуры. Она последовательно проходила следующие стадии развития: монархии первобытного народного государства (Volksstaat), монархии вотчинной (моnarchie seigneuriale), монархии сословной (der monarchische Standestaat), монархии бюрократической (der monarchische Beamtenstaat) и монархии конституционной. Русское государство выполнило огромную цивилизационную работу и создало расеm Rossicam, ту новую аналогию расіs Romanae. На всем протяжении своего исторического развития русская государственность сохраняла самоуправление крестьян и последовательно насаждала самоуправление сословное и всесословное. Так называемый царизм «не знал ни преторьянцев, ни янычар». За исключением нескольких ошибок, важнейшею из которых было русское участие в уничтожении государственной самостоятельности Польши, «направление нашей нынешней политики было непостыдное и доблестное» ${ }^{12}$.

Указав внешние и внутренние затруднения и жертвы, выпавшие на долю России, и объяснив, почему и как она расшаталась, он заканчивает так: «Беспамятство и бесчинство тяжко больного народа было использовано вражьей силой третьего интернационала. Внутрь самого государства внедрился вражеский фронт и стал на пути развития и самой жизни русского народа. И народ должен одолеть этот третий, по историческому счету, фронт так же, как ранее отстаивал себя, свою независимость, свободу и самобытность против двух фронтов - восточного и западного» ${ }^{13}$.

Жизнь и судьба выдающегося ученого принадлежит трем славянским народам - России, Польше и Сербии. В Сербии прошли его последние плодотворные годы, там он и похоронен на Белградском Новом Кладбище, в Сербии его почитают и помнят.

К сожалению, в России сегодня мало кто знает работы Ф.В. Тарановского, а из академической науки практически исчезла дисциплина - славянское право, да и тематика историко-правовых исследований утратила популярность. Интересно, знают ли в Польше об этом выдающемся ученом?

Подводя некоторый итог нашим размышлениям, мы приходим к убеждению, что сравнительное изучение любых институций, а в особенности права, государственной культуры столь же плодотворно, сколь и затруднительно для современных ученых. Мало найдется специалистов, одинаково глубоко разбирающихся в правовой системе разных народов, знакомых с их правовой куль-

12 Ф. Тарановский, Государственная культура России, http://rys-strategia.ru/publ/3-1-0-793, дост. 12.10.2017.

13 Там же. 
турой и первоисточниками. Тем значимее для нас труды выдающихся ученых, рассматривавших явления в их взаимосвязях, взаимовлияниях, воспринимавших славянский мир как геокультурную общность.

\section{Библиография}

Balzer, O., Historya porównawcza praw słowiańskich. Główne kierunki rozwoju nauki i jej istotne zadanie. Lwów 1900 (Studia nad historią prawa polskiego wydawane pod redakcją Oswalda Balzera, tom I, zeszyt 5).

Balzer, O., Nakaz w systemie danin książęcych pierwotnej Polski. Lwów 1928.

Maciejowski, W.A., Historya prawodawstw slowianskich, Tom I, Wydanie drugie. Warszawa 1856.

Šafařík P.J., Über die Abkunft der Slawen nach Lorenz Surowiecki. Ofen 1828.

Taranowski, T., Historja prawa południowo-słowiańskiego, Pamiętnik Historyczno-Prawny pod redakcją Przemysława Dąbkowskiego, t. III, z. 5, Lwów 1927.

Pax Rossica. Русская государственность в трудах историков зарубежья. /Авт.-сост. Е.А. Бондарева. Вече, Москва 2012.

Суровецкий, Л., Исследование начала народов славянских: Рассуждение, чит. в торжеств. заседании Вари. о-ва любителей наук, 24 янв. 1824 г. д. чл. его, Лаврентием Суровецким, пер. с пол. Юстина Белявского, [Предисл.: О. Бодянский], Л. Суровецкий. О-во истории и древностей рос., Москва 1846. 